\title{
O PROFESSOR FORMADOR E AS COMPETÊNCIAS EM TECNOLOGIA DE INFORMAÇÃO E COMUNICAÇÃO:um estudo sobre quais recursos computacionais estes profissionais utilizam na elaboração do seu material didático
}

\author{
TEACHER EDUCATOR AND THE INFORMATION AND \\ COMMUNICATION TECHNOLOGY COMPETENCIES: a study on \\ which computer resources these professionals use in preparing their \\ didactic material
}

\author{
Liliane da Silva Coelho Jacon ${ }^{1}$ \\ Josefina BarreraKalhil ${ }^{2}$
}

\section{RESUMO}

A literatura acadêmica aponta que grande parte dos professores formadores não teve a oportunidade de se habilitar à incorporação das TIC no contexto educacional. Para incorporar as tecnologias de informação e comunicação - TIC -, de forma pedagógica, que resulte em verdadeira modificação no processo de ensino/aprendizagem, é preciso repensar as práticas dos formadores na preparação dos futuros docentes. Desta forma, este artigo aborda como os professores formadores empregam as TIC nos seus afazeres acadêmicos. Para compreendê-los e conhecê-los melhor, fez-se uma pesquisa bibliográfica sobre o perfil do professor formador. Também há um levantamento sobre propostas e projetos de padrões de competência em TIC nos programas de formação docente. Se há propostas e/ou políticas para validação, adoção e aplicação de padrões de competência em TIC nos programas de formação inicial docente, isto implica na necessidade de aproximação com os formadores (professores dos futuros docentes) para viabilizar que os padrões de competência sejam gradualmente inseridos nestes programas. Apresenta também uma pesquisa qualitativa, cujos dados foram obtidos através de um questionário entre os formadores de professores dos cursos de licenciatura e bacharelado em física e química da Universidade Federal de Rondônia. O objetivo desta pesquisa foi apontar as formas de acesso e as formas de utilização das TIC no processo de elaboração de material didático como apoio pedagógico. A pesquisa revela que os docentes da Universidade Federal de Rondônia possuem alta qualificação acadêmica, possuem computadores pessoais que carregam para o trabalho e, principalmente, que utilizam diversificadas modalidades de programas computacionais para elaborar seu material didático pedagógico.

Palavras-chave: Professor formador, competências em TIC, material didático pedagógico

\footnotetext{
${ }^{1}$ Professora do departamento de Ciência da Computação - Campus de Porto Velho/RO e doutoranda do Programa de Pós Graduação da Rede Amazônica de Educação em Ciências e Matemática - PPGECEM/ REAMEC liliane285@hotmail.com

${ }^{2}$ Professora Doutora do departamento de Física da Universidade Estadual do Amazonas UEA e do Programa de Pós Graduação da Rede Amazônica de Educação em Ciências e Matemática - PPGECEM/REAMECjosefinabk@ gmail.com

AMAZÔNIA - Revista de Educação em Ciências e Matemáticas V.8 - no 15 - jul. 2011/dez. 2011, p.27-44.
} 


\section{ABSTRACT}

The academic literature suggests that most of the teacher educatorshave not had the opportunity to habilitate themselves to the incorporation of ICT in the educational context. In order to incorporate the information and communication technologies - ICT -in a pedagogical way that results in real modification in the teaching/learning process, it is necessary to rethink the practices of teacher trainers in the preparation of future teachers. Thus, this article discusses how teacher trainers employ ICT in their academic affairs. In order to understand them and know them better, we did a literature search on the profile of the teacher trainer. There is also a survey about proposals and projects of standards of competence in ICT in teacher education programs. If there are proposals and/or policies for validation, adoption and application of standards of competence in ICT in initial teacher training programs, this implies the need for an approximation with the trainers (teachers of future teachers) to ensure that the standards of competence are gradually included in these programs. It also presents a qualitative survey, whose data were obtained through a questionnaire among the trainers of teachers from licentiateships and bachelor courses in physics and chemistry at the Federal University of Rondônia. The objective of this research was to identify which are the forms of access and ways of using ICT in the process of preparing instructional materials for pedagogical support. The research reveals that the professors of the Federal University of Rondônia have high academic qualifications, have personal computers which they carry to work and, especially, that they use diverse modalities of computer programs to develop their educational courseware.

Keyword:teachers trainers, competence in ICT, pedagogical teaching materials

\section{INTRODUÇÃO}

No cotidiano dos cidadãos, as inovações tecnológicas são incorporadas crescentemente em processos e atividades, tais como: compras online, informações e certificações públicas, consultas e movimentações bancárias, eleições, declaração do imposto de renda etc. A consequência disso é o surgimento de novas necessidades de aprendizagem nos mais diversos segmentos da sociedade e, em especial, na educação. Os professores são pressionados cada vez mais a incorporar a tecnologia para criar recursos pedagógicos informáticos, mas que não fizeram parte de sua história como alunos, nem de sua formação como professores.

Richit (2010) afirma que a maioria dos professores formada na década de 90 não teve acesso às tecnologias, assim como "a formação tecnológica que têm vivenciado ao longo da carreira, quando recebem, não é adequada e suficiente para que as incorporem na prática" (p.31). Além disso, acrescenta ela, na década atual, o uso desses recursos nas licenciaturas ainda é restrito, quando não negligenciado.Bastos (2010) alerta que a formação inicial docente não deve se restringir à introdução de temas específicos sobre a incorporação tecnológica na educação, mas destaca que é preciso integrar processos de reforma educacional que resultem em verdadeira modificação das práticas dos formadores na preparação dos futuros professores. Segundo ela...

\footnotetext{
"enquanto a formação dos docentes não for capaz de incorporar o uso pedagógico das TIC, [...] sua mobilização para o ensino/aprendizagem nas escolas será sempre um enxerto de algo estranho e feito de fora para dentro" (p.33).
} 
O uso das TIC (Tecnologia de Informação e Comunicação) no processo de ensinoaprendizagem depende diretamente e primordialmente da atitude dos professores, embora não seja este o fator único. Para fazer uso desta tecnologia, as TIC requerem um saber específico para que se possa lançar mão delas no processo de ensino/aprendizagem. Segundo Bastos (2010),

\footnotetext{
"Grande parte dos formadores de docentes (da América Latina) nem sequer está no grupo dos chamados "imigrantes digitais", isto é, não tiveram a oportunidade de se habilitar à adoção das novas tecnologias anos após sua própria formação docente e exercício profissional em escolas desprovidas dessa tecnologia (Bastos, p.6)
}

Diante disso, cabem aqui alguns questionamentos: se uma das razões pela qual os professores não conseguem incorporar os recursos pedagógicos informáticos na sua prática em sala de aula se deve à formação inicial inadequada e/ou insuficiente destes profissionais, então como é a prática dos formadores de formadores (ou os professores das licenciaturas)? Eles utilizam a tecnologia na sua prática pedagógica (ou não)? Ou ainda, se eles a utilizam, o que e como eles a utilizam? Quais recursos informáticos eles utilizam, por exemplo, na elaboração do seu material didático como apoio pedagógico?

Para tentar responder a estes questionamentos, este artigo é dividido em 3 capítulos. $\mathrm{O}$ primeiro capítulo aborda o perfil do professor universitário, salientando as características e as fragilidades apresentadas por este profissional. Em seguida, o capítulo dois discute quais são as competências e habilidades necessárias ao professor para incorporar as TIC no processo de ensino aprendizagem. $\mathrm{O}$ terceiro capítulo apresenta a pesquisa realizada com os professores dos departamentos de física e química da Universidade Federal de Rondônia sobre as formas de acesso e as formas de utilização das TIC para elaboração de material didático como apoio à prática pedagógica. E nas considerações finais são apresentadas algumas reflexões desta pesquisa.

\title{
O PERFIL DO PROFESSOR UNIVERSITÁRIO
}

\begin{abstract}
O papel do professor formador merece muito destaque, pois ele é responsável por nutrir esperanças, por encorajar sonhos e por mediar todo o processo de formação (Silva \& Oliveira, 2009, p.54).
\end{abstract}

Krasilchik (1996) cita que, a partir dos anos 70, houve uma expansão de instituições privadas de $3^{\circ}$ grau, decorrente dos movimentos estudantis que exigiam a democratização do ensino superior. Pimenta e Anastasiou (2008) citam a expansão quantitativa da educação superior e o consequente aumento do número de docentes: "dados da Unesco demonstram que o número de professores universitários, no período de 1950 a 1992, saltou de 25 mil para um milhão, isto é, aumentou 40 vezes". Apesar do grande crescimento de cursos superiores no país, existe pouca produção acadêmica na área de formação de professores de ensino superior no Brasil (Mello \& Oliveira, 2005, p.69). Por sua vez, a docência no ensino superior é ainda território que só recentemente passou a fazer parte desse debate (Echeverria et al. 2010, p.259).

Pimenta e Anastasiou afirmam que estes profissionais, em sua maioria, são professores improvisados, não preparados para desenvolver a função de pesquisadores e sem formação 
pedagógica. Muitos professores universitários receberam apenas formação técnica, são bacharéis das suas respectivas carreiras e não possuem curso de licenciatura na sua formação pedagógica (Pimenta \& Anastasiou, 2002, p.107). Nestes casos, a capacitação para o ensino superior fica a cargo dos cursos de especialização, que qualificam os indivíduos para a docência. No entanto, o objetivo destes cursos é o de preparar para a pesquisa além de serem direcionados para a matéria específica, não se preocupando com as questões didáticas (Alves \& Oliveira, 2011, p.3).

A formação dos docentes de nível superior, em grande parte, fica a cargo dos programas de mestrado e doutorado, ou seja, programas de pós graduação stricto sensu (Mello \& Oliveira, 2005). Quando existe alguma formação para a docência neste grau de ensino, esta se encontra circunscrita "a uma disciplina de Metodologia do Ensino Superior", com carga horária média de 60 horas" (Anastasiou, 2002 apud Mizukami \& Ferenc, p.4). Neuenfeldt (2011) alerta para a fragilidade deste profissional que, para atuar como professor, quase não teve oportunidade para se aperfeiçoar nesse aspecto. A preocupação deste profissional é a de transmitir o conhecimento, faltando-lhe a parte pedagógica. As universidades deveriam ir além do que é exigido pela lei de diretrizes e bases (LDB), que explicita que a qualificação do professor universitário fica a cargo dos cursos de mestrado e doutorado. Nesse sentido, segundo Pachane (2005) os cursos de mestrado e doutorado acabam

\footnotetext{
“...por reproduzir uma situação em que atividades de ensino e pesquisa são realizadas de modo dissociado, ou mesmo equivocado, e por perpetuar a noção de que para ser professor basta conhecer a fundo determinado conteúdo e, no caso específico do ensino superior, ser um bom pesquisador"(Pachane, 2005,p.14).
}

A parte pedagógica não é privilegiada nos programas de mestrado e doutorado, que habilita o profissional a atuar no ensino superior. Neuenfeldt (2011) alerta que

\footnotetext{
"um dos problemas é que muitos professores universitários nunca tiveram práticas docentes em instituições além da universidade, sua trajetória profissional está alicerçada apenas nos modelos de professores que tiveram e suas experiências são constituídas apenas enquanto alunos" (Neuenfeldt, p.4).
}

Na LDB existe a preocupação com os profissionais que irão atuar no ensino fundamental e médio, cuja obrigatoriedade de estágio com prática de ensino para a formação do professor está retratada na LDB, Lei 9.394/96, em seus artigos 65 e 66, da seguinte forma:

Artigo 65 - "a formação docente, exceto para educação superior, incluirá prática de ensino de, no mínimo, trezentas horas."

Artigo 66 - "a preparação para o exercício do magistério superior far-se-à em nível de pós-graduação, prioritariamente em programas de mestrado ou doutorado (Alves \& Oliveira, p.3)

A interpretação destes artigos é a de que a preparação para o ensino superior fica a cargo dos programas de mestrado e doutorado e a exigência de prática supervisionada é apenas para a formação dos docentes do ensino fundamental e médio.

Segundo Alves \& Oliveira (2011), os professores universitários aprendem com a prática, levando em conta o conhecimento que o indivíduo possui do conteúdo, esquecendo-se da importância de uma formação pedagógica adequada. E acrescentam que, para atuar no ensino superior... 
“é necessário conhecimento técnico, ou domínio do conteúdo, pesquisar constantemente, além de ser um elemento conscientizador, sendo formador de opiniões. Estas 3 características devem estar aliadas à ação pedagógica para que o trabalho do professor do ensino superior seja desenvolvido com eficácia" (Alves \& Oliveira, 2011).

$\mathrm{Na}$ pesquisa realizada por Mello \& Oliveira (2005), com professores do ensino superior, observou-se "supervalorização" da pesquisa (Mello \& Oliveira, p.65). Pachane afirma que, na pós-graduação, a tendência é priorizar as atividades para a condução de pesquisas, perpetuando-se a crença de que para ser professor basta conhecer a fundo determinado conteúdo e, na educação superior, ser um bom pesquisador (Pachane, 2005, p.12).

O Ministério da Educação (MEC) faz exigências nas instituições de ensino superior (IES) com relação à titulação dos docentes. As IES tentam se adequar de acordo com o que é cobrado do MEC, obedecendo às porcentagens exigidas sem, no entanto, preocupar-se com a formação pedagógica destes colaboradores. Pimenta e Anastasiou (2008) salientam com relação à titulação necessária para o ensino superior:

\footnotetext{
"No que se refere à exigência de titulações, o decreto 2.207/97 determina que, no segundo ano de vigência, as instituições de ensino superior deverão contar com 15\% de seus docentes titulados na pós-graduação, dos quais $5 \%$ doutores, pelo menos; no quinto ano de vigência, com $25 \%$, dos quais $10 \%$ de doutores, pelo menos; e no oitavo ano de vigência, com um terço, dos quais $15 \%$ de doutores, pelo menos" (Pimenta e Anastasiou, 2008, p.40).
}

Mizukami \& Ferenc (2005) afirmam que os docentes do ensino superior não apresentam uma identidade única, decorrente da diversidade e da multiplicidade da educação superior brasileira. Uma vez que o profissional se encontra dentro da instituição, ele é desafiado e cobrado a investir na sua permanente formação para a pesquisa e, assim, a aprendizagem dos saberes para o ensinar fica a critério de iniciativas e compromissos individuais (Morosini apud Mizukami \& Ferenc, p.5). Sobre o processo de aprendizagem do ensinar por professores universitários, estes autores afirmam que a maioria cita seus professores como referências à prática de ensinar.

\section{TECNOLOGIA \& EDUCAÇÃO: ALGUNS PROJETOS E PROPOSTAS DE PADRÕES DE COMPETÊNCIA EM TIC PARA DOCENTES}

Gil-Perez \& Carvalho (1993) enfatizam que a preparação docente deve estar associada as tarefas de pesquisa e inovação permanente. Os formadores percebem as rápidas mudanças da sociedade que repercutem no âmbito educacional, tais como: mudança do conhecimento científico, do condutivismo para o cognitivismo, desenvolvimento acelerado da sociedade, rápidas mudanças nos meios de comunicação e tecnologias. Todas essas mudanças repercutem na formação e no ensino, sejam eles na área de ciências ou não (Sá-Chaves, 2002 apud Silva e Ferreira).A incorporação das TIC na formação docente é um imperativo tanto para a própria formação quanto para a aprendizagem de seus futuros alunos. A contribuição que os recursos tecnológicos, em especial, a informática, têm trazido ao ensino de Química, por exemplo, por meio das simulações, pode colaborar para a reversão de uma situação de afastamento desenvolvida por parte dos alunos em relação ao monólogo do professor treinando macetes e dicas de como decorar fórmulas e nomes de substâncias (Gabini e Diniz, p.346). 
Para Bastos (2010), o desafio básico é saber quais são as capacidades docentes que são requeridas e quais as mudanças que devem ser produzidas na cultura escolar. É neste sentido que se coloca a necessidade de definir padrões de competências em TIC para professores.

\begin{abstract}
“Os padrões estabelecem um nível de conhecimento desejável e o que é considerado indispensável para que o docente possa mobilizar os recursos tecnológicos disponíveis na escola - ou no seu entorno - em favor do ensino e da aprendizagem. A existência de padrões de competência permite identificar à medida que os docentes e suas escolas se aproximam - ou se afastam - desse estado desejado" (Bastos, 2010, p.42).
\end{abstract}

A seguir, serão mencionadas duas referências de padrões de competência em TIC para docentes: o projeto ICT-CST da Unesco e a proposta do governo chileno baseado na Rede Enlaces. É importante esclarecer que ainda não existe uma proposta brasileira.

\title{
Projeto ICT-CST da Unesco
}

O projeto da Unesco - Information and Communication Technologies - Competency Standards for Teachers - oferece um completo referencial para parâmetros de competência em TIC de docentes com o objetivo geral de melhorar a prática docente, embora não distingua explicitamente se os padrões são para a formação inicial docente ou para a formação continuada (Bastos, 2010, p.47). O projeto recebeu contribuição da International Society of Tecnology in Education - ISTE, Microsoft, Cisco, Intel, Universidade do estado da Virgínia e está disponível em HTTP://www.unesco.org/en/competency-standards-teachers.

Segundo Bastos (2010), este projeto gerou 3 publicações: marco político, os módulos dos padrões de competência e as diretrizes de execução. A publicação sobre marco político define 3 abordagens adotadas como vinculação entre política educacional com relação às TIC na educação e desenvolvimento econômico (Bastos, p.47). São elas:

\footnotetext{
alfabetização em tecnologia: trata da concepção que a meta política da educação é aumentar o entendimento tecnológico dos estudantes, cidadãos e da força de trabalho incorporando as habilidades tecnológicas ao currículo;

aprofundamento do conhecimento: tem como meta política para o uso da TIC na educação aumentar a habilidade dos estudantes, cidadãos e da força de trabalho para utilizar o conhecimento de forma a agregar valor à sociedade e à economia, aplicando-o para resolver problemas complexos do mundo real;

geração do conhecimento: vê como meta política do uso de TIC na educação aumentar a capacidade dos estudantes, cidadãos e da força de trabalho para inovar, produzir novos conhecimentos e se beneficiar desse novo conhecimento.
}

As três abordagens e seis componentes do sistema educacional (currículo e avaliação, pedagogia, tecnologia, organização e administração e desenvolvimento profissional) formam a matriz de módulos de competência. Os módulos apresentam as competências e habilidades docentes que correspondem a modalidades com que cada componente do sistema educacional reflete a respectiva abordagem. Neste artigo, o componente pedagogia é de interesse para esta pesquisa e, portanto, é descrito com mais detalhes na tabela 1. 


\begin{tabular}{|c|c|c|}
\hline ABORDAGEM & Componente Pedagogia & Habilidade do Professor \\
\hline $\begin{array}{l}\text { Alfabetização } \\
\text { tecnologia }\end{array}$ & $\begin{array}{llr}\text { Integração } & \text { de diversas } \\
\text { tecnologias, ferramentas e } \\
\text { conteúdos } & \text { digitais nas } \\
\text { atividades de apoio ao } \\
\text { ensino }\end{array}$ & $\begin{array}{l}\text { Requerem saber onde, como, } \\
\text { quando (e quando não) usar a } \\
\text { tecnologia nas atividades de sala de } \\
\text { aula e nas apresentações }\end{array}$ \\
\hline $\begin{array}{l}\text { Aprofundamento do } \\
\text { conhecimento }\end{array}$ & $\begin{array}{l}\text { Aprendizado colaborativo, } \\
\text { com base em problemas e } \\
\text { projetos que alunos } \\
\text { exploram um conteúdo e } \\
\text { usam seu conhecimento } \\
\text { para resolver problemas e } \\
\text { situações rotineiras quanto } \\
\text { complexas }\end{array}$ & $\begin{array}{l}\text { Habilidade para manter o aluno como } \\
\text { foco e estruturar as tarefas-desafio, } \\
\text { orientando o entendimento do aluno e } \\
\text { apoiando projetos colaborativos; } \\
\text { ajudar os alunos a criar, realizar e } \\
\text { monitorar os planos, projetos e } \\
\text { soluções. }\end{array}$ \\
\hline $\begin{array}{l}\text { Geraçãodo } \\
\text { conhecimento }\end{array}$ & $\begin{array}{l}\text { Autogestão. Alunos trabalham } \\
\text { em uma comunidade de } \\
\text { aprendizagem onde estão } \\
\text { permanentemente envolvidos na } \\
\text { construção de suas próprias } \\
\text { habilidades de aprendizagem e } \\
\text { compartilhando r do } \\
\text { desenvolvimento } \\
\text { habilidades de seus pares. }\end{array}$ & $\begin{array}{l}\text { Habilidade permitirá que os } \\
\text { professores modelem os processos } \\
\text { de forma clara, estruturem as } \\
\text { situações nas quais os alunos } \\
\text { aplicam suas habilidades cognitivas } \\
\text { e ajudem-nos a adquiri-las. }\end{array}$ \\
\hline
\end{tabular}

\section{Padrão do governo chileno baseada na Rede Enlaces (Centro de educação e tecnologia do ministério da Educação do Chile) de 2008}

O governo chileno decidiu elaborar seu próprio padrão baseado na sua vasta experiência nacional denominada "Rede Enlaces". Trata-se de um projeto desenvolvido pelo Centro de Educação e Links Tecnologia do Ministério da Educação do Chile, com o apoio da UNESCO. Trata-se do resultado de um estudo realizado por profissionais do (Salvat et al., 2008; Bastos, 2010).

A formação de docentes é vista como um processo que começa com a formação inicial e se estende na formação continuada, sendo que os padrões de competência em TIC definem o perfil de manejo das tecnologias que um futuro professor deveria adquirir no processo de sua formação inicial, isto é, durante o curso superior (Bastos, 2010,p.49). Os padrões baseiam-se na experiência da Rede Enlaces e foram rearticuladas em cinco dimensões, a saber:

Técnica: os futuros docentes demonstram um domínio das competências associadas ao conhecimento geral das TIC e do manejo das ferramentas de produtividade (processador de texto, planilha eletrônica, apresentações) e Internet, desenvolvendo habilidades e destrezas para a aprendizagem permanente de novo hardware e software

Gestão escolar: os futuros docentes utilizam as TIC para apoiar seu trabalho administrativo tanto no nível de sua gestão docente quanto no apoio à gestão do estabelecimento escolar

Desenvolvimento profissional: os futuros docentes usam as TIC como meio de especialização e de desenvolvimento profissional, informando-se e acessando diversas fontes para melhorar suas práticas e facilitando a troca de experiências que contribuem, mediante um processo de reflexão que envolva diversos atores educativos, para o alcance de melhores processos de ensino e aprendizagem 
Aspectos éticos, legais e sociais: os futuros docentes conhecem, apropriam-se e difundem entre seus estudantes os aspectos éticos, legais e sociais relacionados ao uso dos recursos informáticos e conteúdos disponíveis na internet, agindo de maneira consciente e responsável em relação aos direito, cuidados e respeitos que devem ser considerados no uso das TIC.

Pedagógica: os futuros docentes adquirem e demonstram formas de aplicar as TIC no currículo escolar vigente como uma forma de apoiar e expandir a aprendizagem e o ensino

Na dimensão PEDAGÓGICA, está o foco de interesse deste artigo. A seguir, são descritos os 7 padrões que a compõem, conforme Salvat et al (2008):

E1: conhecer as implicações do uso de tecnologias na educação e as possibilidades para apoiar sua grade curricular.

E2: planejamento e criação de ambientes de aprendizagem com TIC para o desenvolvimento curricular.

E3: utilizar as TIC na preparação de material didático para apoiar as práticas pedagógicas e assim melhorar seu desempenho profissional futuro.

E4: Implementação de experiências de aprendizagem com o uso de TIC para o ensino do currículo.

E5: avaliar recursos tecnológicos para incorporá-los nas práticas pedagógicas.

E6: avaliar os resultados obtidos no planejamento e uso de tecnologia para a melhoria na aprendizagem e desenvolvimento de habilidades cognitivas.

E7: apoiar os processos de ensino e aprendizagem através do uso de ambientes virtuais.

\section{MATERIAL E MÉTODOS}

Para averiguar a dimensão pedagógica nos cursos de licenciatura e bacharelado em Física e Química da Unir, a pesquisa se baseou no padrão E3 do governo chileno (Rede Enlaces). O padrão E3 define o perfil do manejo das tecnologias no processo de elaboração do material didático.

A pesquisa foi desenvolvida na Universidade Federal de Rondônia - UNIR -, no mês de abril de 2012. O departamento de Física é composto por 9 professores e o departamento de Química é composto por 10 professores. Dos 20 professores desses dois departamentos, apenas 9 responderam ao questionário (anexo).

Foi aplicado um questionário composto por 14 (catorze) questões divididas em 3 partes: (A) identificação do docente, (B) formas de acesso e (C) formas de utilização do computador.

\section{(A) Identificação dos docentes}

Responderam ao questionário 4 professores do departamento de química e 5 professores do departamento de física, num total de 9 professores. A idade média dos docentes é 40 anos, sendo todos eles concursados e pertencentes ao quadro efetivo da universidade (dedicação exclusiva). Com relação à titulação, 2 docentes possuem pós-doc, 5 são doutores e apenas 2 são mestres (mas ambos com o doutorado em andamento). O tempo médio de atuação no magistério superior é de 9 anos. 
Dos 5 professores do departamento de física que responderam ao questionário, 3 são apenas bacharéis e 2 possuem tanto a licenciatura bem como o bacharelado. Dos 4 professores do departamento de química, 3 são apenas bacharéis e um possui apenas a licenciatura.

(B) Formas de acesso

Todos utilizam o computador nos seus afazeres acadêmicos e todos possuem computador pessoal próprio. Seis docentes utilizam somente o próprio computador pessoal para realizar seus afazeres acadêmicos e apenas três utilizam tanto o computador pessoal bem como os equipamentos que a universidade disponibiliza nos departamentos. Tanto na universidade, como em suas casas, os docentes utilizam equipamentos com conexão com a internet. A média de uso é de 6,5 horas diárias.

Dos nove docentes pesquisados, 8 não possuem tablet e não acessam a internet via celular, com exceção de um único professor. Este professor, excepcionalmente, possui um tablet, além de acessar a internet via celular, embora não utilize o laboratório de informática da universidade para ministrar suas aulas.

Observou-se que seis docentes utilizam o laboratório de informática e apenas três não o fazem.

(C) Formas de utilização do computador

Na questão sobre a habilidade dos docentes no uso do computador para atender suas atividades profissionais, observou-se que 8 docentes a consideram suficiente, isto é, na medida certa. Apenas um único docente considerou sua habilidade muito maior do que o necessário (para realização de atividade docente). Sobre a habilidade de uso do computador para atender às suas necessidades pessoais, observou-se um pequeno acréscimo nesta percepção, cujos resultados foram: cinco julgam sua habilidade suficiente, três julgam sua habilidade maior que o necessário e, apenas um julgou sua habilidade muito maior do que o necessário. No gráfico da figura 1, a habilidade profissional é ilustrada na cor vermelha e a habilidade para uso pessoal encontra-se na cor azul.

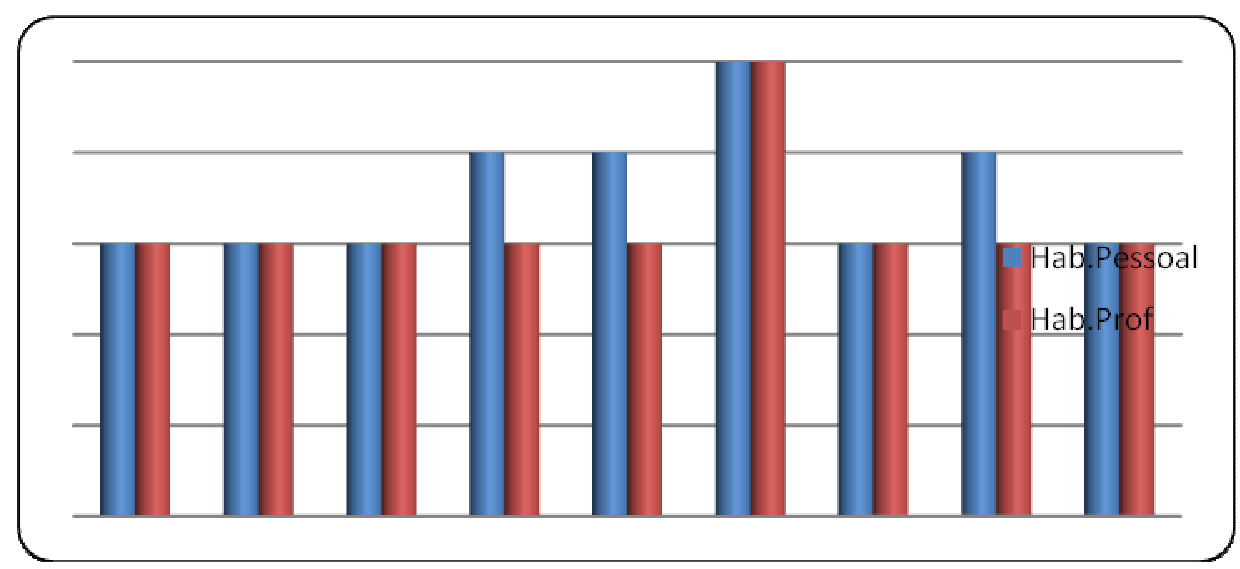

Figura 1- Percepção dos docentes relacionado à habilidade deles no uso do computador para atender suas necessidades pessoais e atividades profissionais

Para conhecer como o docente utiliza as TIC na preparação do seu material didático para apoiar suas práticas pedagógicas, foram definidas 7 modalidades de utilização. Para cada modalidade, foi solicitado que o docente estabelecesse um valor numa escala entre 0 e 10 (escala Likert). Caso a modalidade fosse fortemente utilizada, então o valor máximo atribuído na escala é 10. Quanto menor o valor da escala, menor a utilização da modalidade em questão. Valor 0 (zero) significa que não é utilizada tal modalidade.

As sete modalidades são descritas na Tabela 2. 
Tabela 2: Uso do computador para preparação de material didático como apoio à prática pedagógica

\begin{tabular}{|c|c|}
\hline Modalidades de utilização das TIC para elaboração do material didático & Resultados obtidos \\
\hline $\begin{array}{l}\text { A- ................................................................ (tilizo processador de } \\
\text { texto para a produção de material didático de apoio às minhas atividades } \\
\text { pedagógicas (planos, provas, módulos de aprendizagem, materiais de } \\
\text { leitura) }\end{array}$ & $\begin{array}{c}\text { Média }=9,1 \\
\text { Desvio padrão }=1,7\end{array}$ \\
\hline $\begin{array}{l}\text { elanilha } \\
\text { eletrônica na preparação de material didático de apoio aos processos de } \\
\text { ensino e aprendizagem em meu setor curricular }\end{array}$ & $\begin{array}{c}\text { Média }=5,8 \\
\text { Desvio padrão }=3,7\end{array}$ \\
\hline $\begin{array}{l}\text { Capoiar o ensino e a aprendizagem de conteúdos de meu setor curricular } \\
\text { utilizando elementos textuais, gráficos e multimídia contidos em software } \\
\text { de apresentação }\end{array}$ & $\begin{array}{c}\text { Média }=7,2 \\
\text { Desvio padrão= } 3,5\end{array}$ \\
\hline $\begin{array}{l}\text { computacionais para o desenvolvimento de recursos multimídia de apoio } \\
\text { às atividades pedagógicas (elaboração de páginas web, uso de editores de } \\
\text { páginas web e/ou aplicações para seu desenvolvimento. Por exemplo } \\
\text { dreamweaver. }\end{array}$ & $\begin{array}{c}\text { Média }=3,8 \\
\text { Desvio padrão= }=3,5\end{array}$ \\
\hline $\begin{array}{l}\text { em plataformas de trabalho colaborativo com o fim de criar espaços } \\
\text { virtuais de aprendizagem e reconhecer o potencial educativo das } \\
\text { comunidades virtuais (Moodle, Teleduc, webquest) }\end{array}$ & $\begin{array}{c}\text { Média }=1,1 \\
\text { Desvio padrão= } 3,0\end{array}$ \\
\hline $\begin{array}{l}\text { Software } \\
\text { educativo específico da minha área de conhecimento, como apoio ao } \\
\text { processo de ensino aprendizagem com seus alunos }\end{array}$ & $\begin{array}{c}\text { Média geral }=5,4 \\
\text { Desvio padrão }=4,2\end{array}$ \\
\hline $\begin{array}{l}\text { dados para armazenar e consultar informações da minha área do } \\
\text { conhecimento (ex; MySQL, Oracle, Access, etc) }\end{array}$ & $\begin{array}{c}\text { Média }=0,8 \\
\text { Desvio padrão=1,7 }\end{array}$ \\
\hline
\end{tabular}

Para cada modalidade de software utilizado (vide Tabela 2), foi calculada a média e o desvio padrão. O desvio padrão indica o grau de variação de um conjunto de elementos, ou seja, indica o grau de variação no uso de uma determinada modalidade. Por exemplo, o software Processador de Texto, cuja média foi 9,1 e desvio padrão foi de 1,7, demonstra que é uma modalidade muito utilizada entre todos os docentes. Já a modalidade sobre a utilização de plataformas de trabalho colaborativo, cuja média foi 1,1 (quase não é utilizada) e com desvio padrão 3,0, significa que apenas um único professor, entre os 9 pesquisados, utiliza tal modalidade, sendo desconhecida ou não utilizada pelos demais. 


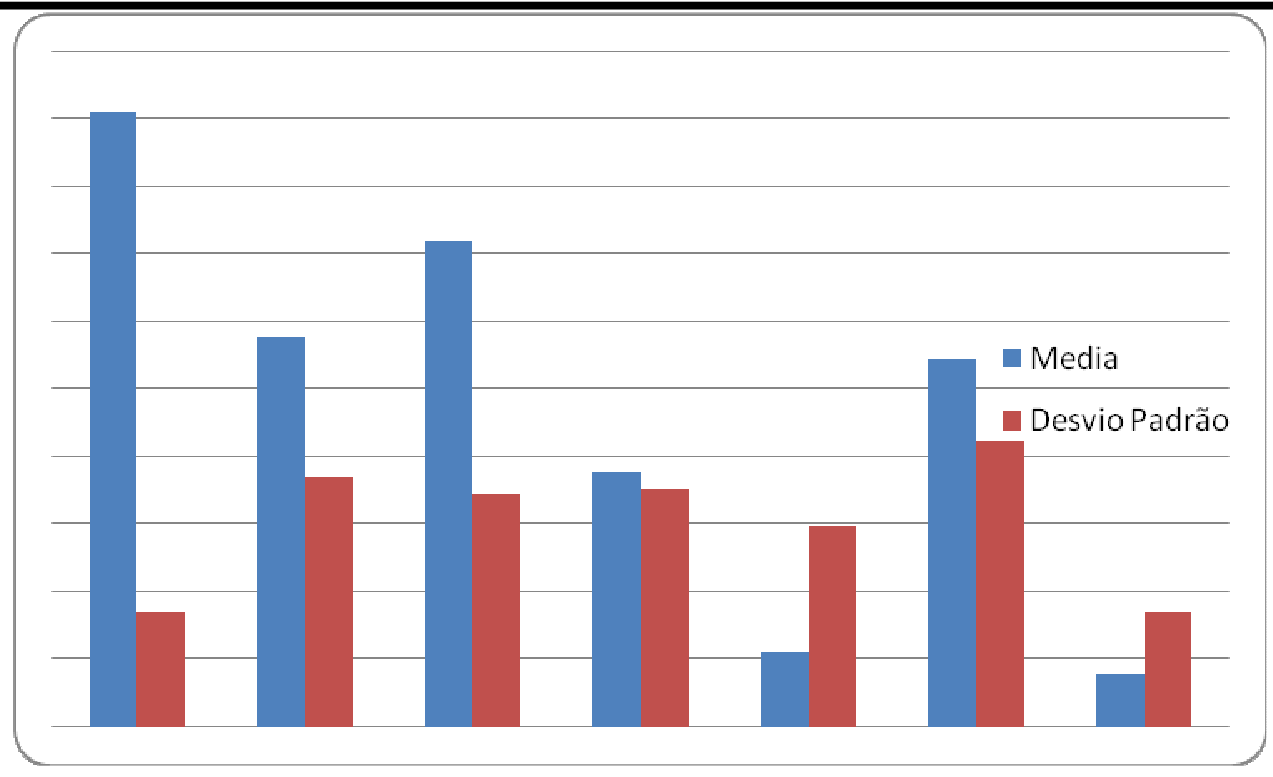

Figura 2 - Modalidades de utilização das TICs na elaboração do material didático

As ferramentas de produtividade (processador de texto, planilha eletrônica e apresentações) correspondem aos itens $\mathrm{A}, \mathrm{B}$ e $\mathrm{C}$ da tabela 2 . O gráfico da figura 2 ilustra as 7 modalidades (eixo $\mathrm{X}$ ) versus a escala de utilização (eixo Y), demonstrando a forte utilização das ferramentas de produtividade.

\section{DISCUSSÃO}

Observou-se que os professores, sem exceção, utilizam o computador com acesso à internet em seu cotidiano (universidade e residencial). Inclusive, alguns utilizam o computador pessoal (adquirido com recurso próprio) na universidade.

Dos 9 professores que responderam o questionário, 4 não utilizam o laboratório de informática. Isso leva a nos crer que, para esses, o material elaborado digitalmente é distribuído entre os discentes, numa das seguintes formas abaixo:

disponibilizado na web para consulta e/ou impressão;

o material é impresso para ser discutido/trabalhado em sala de aula;

é apresentado na sala de aula por meio de data-show.

Na questão sobre o uso do computador para preparação de material didático como apoio à prática pedagógica, foram relacionados diversos tipos de software, tais como: software de produtividade, ambientes colaborativos (moodle, teleduc), software específico da área de conhecimento do docente, banco de dados, página web com recursos multimídia. Evidentemente que não se espera que um professor utilize todos esses softwares simultaneamente. $O$ que esta pesquisa procurou levantar e conhecer eram quais as modalidades de programas/recursos informáticos que o docente utiliza para elaborar o seu material didático.

Os softwares de produtividade (processador de texto, planilha eletrônicas e softwares de apresentação) são aqueles que obtiveram maior pontuação e, em especial, o processador de texto obteve a maior média de utilização entre as demais modalidades. Os processadores de texto são utilizados para elaboração de planos, provas, módulos de aprendizagem e materiais de leitura. A segunda maior pontuação de utilização foi a modalidade de software de 
apresentação (slides), também empregada para criar apresentações dos conteúdos do setor curricular. A planilha eletrônica é utilizada para realizar cálculos (emprego de fórmulas e análises estatísticas) e também para criar gráficos. Esta modalidade (planilha) é utilizada fortemente por 4 professores, utilizada pouco por outros 2 e desconhecida para os demais (3 professores).

Observou-se a baixa utilização de plataformas de trabalho colaborativo com o fim de criar espaços virtuais de aprendizagem e do emprego do potencial educativo das comunidades virtuais (exemplo: Moodle, teleduc, WebQuest). Apenas um único professor do departamento de química utiliza ambientes colaborativos virtuais como apoio pedagógico, sendo que a grande maioria (8 professores) desconhecem ou não utilizam esta modalidade.

Embora não utilizem plataformas de trabalho colaborativo, 4 professores elaboram sites com recursos multimídia, ou seja, utilizam a Web como apoio na elaboração do seu material didático, sendo que para os demais (5 docentes) esta é uma modalidade desconhecida ou de pouca utilização.

Na modalidade de uso de software específico da área de conhecimento do docente, 5 docentes utilizam muito esta modalidade (entre os cinco docentes que utilizam esta modalidade, obteve-se média 8,4 ), pois os 4 outros professores também não a utilizam ou desconhecem esta modalidade.

Com relação à utilização de banco de dados (criação e manutenção de uma base de dados), observou-se que é uma modalidade desconhecida ou de quase nenhuma utilização.

\section{CONSIDERAÇÕES FINAIS}

Para fazer a pesquisa entre os docentes dos departamentos de física e química da Unir, foi realizado, primeiramente, um levantamento do perfil do formador dos formadores, ou seja, os professores universitários. Dos 9 professores pesquisados, 3 são licenciados.

Nesta pesquisa, observou-se que eles têm em comum a alta qualificação acadêmica, utilizam o computador diariamente por várias horas (média de 6,5 hs), e a idade média é de 40 anos. $\mathrm{O}$ uso de tablets ou conexão à internet via celular ainda é uma novidade (apenas um faz uso destes recursos). E que $67 \%$ utilizam o laboratório de informática da universidade para ministrar suas aulas.

Os docentes dos departamentos de química e física da Unir ultrapassaram o nível técnico propriamente dito e utilizam o computador pessoal com acesso à internet e/ou da universidade de forma intensiva no seu cotidiano acadêmico. Ou seja, não cabe aqui o discurso que o uso desses recursos na licenciatura é restrito e/ou negligenciado. A questão é até que ponto essa utilização é feita de forma pedagógica. Desta forma, foram pesquisados alguns padrões de competências em TIC para a formação de docentes e averiguados quais recursos computacionais estes profissionais utilizam na preparação do seu material didáticopedagógico.

Os recursos didáticos digitais mais utilizados pelos professores foram os softwares de produtividade sendo que, dos nove docentes pesquisados, cinco utilizam softwares específicos da sua área de conhecimento para o desenvolvimento de suas atividades educacionais. Os docentes pesquisados demonstram empregar modalidades diversificadas na elaboração do seu material didático (especialmente softwares de produtividade), demonstrando também que possuem nível técnico suficiente e satisfatório no domínio das ferramentas computacionais, 
com exceção das plataformas de trabalhos colaborativos virtuais, tais como moodle, teleduc, webquest etc., bem como não utilizam banco de dados em suas atividades acadêmicas.

No entanto, a pesquisa não aprofundou em questões de planejamento, ou como os docentes selecionam estratégias de aprendizagem que utilizem recursos de web e/ou software educativo e/ou ferramenta de produtividade. A questão levantada é se há possibilidade de que as TIC estejam sendo utilizadas no ensino apenas como ferramentas de produtividade, sem alterar significativamente o processo de ensino/aprendizagem. Como sugestão de trabalho futuro, é preciso pesquisar como os docentes identificam aprendizados esperados e possíveis de desenvolver com a incorporação das TIC e verificar também como os docentes relacionam ferramentas e recursos tecnológicos ao alcance da aprendizagem esperada e dos conteúdos de planos e programas de estudo em vigor. A partir desta averiguação, então, será possível identificar com mais clareza como os docentes utilizam efetivamente as TIC durante sua prática docente.

\section{REFERÊNCIAS BIBLIOGRÁFICAS}

Alves, Amália Cardoso; Oliveira, Wenderson Silva Marques de. A formação do professor do ensino superior. In: HTTP://faculdadeatenas.edu.br/ arquivos/NucleoIniciacaoCiencia/RevistaCientifica/REVISTA $\quad$ CIENTIFICA $\quad 2010 / 13$ A FORMACAO DO PROFESSOR.pdf Acessado em 14/novembro/2011.

Bastos, Maria Inês. O impacto das TICs na educação: o desenvolvimiento de competências em TIC para a educação na formação de docentes na América Latina. Org.Unesco. OREALC. Brasília. abril 2010.

Echeverría, A.R.;Benite, C.R.M.; Benite, A.M.C. A pesquisa na formação de formadores de professores: em foco, a educação química. Revista Química Nova na escola. Vol.32, nro.4, novembro/ 2010. pp.257-266

Gabini, W.S. \& Diniz, R.E. da S. Os professores de química e o uso do computador em sala de aula: discussão de um processo de formação continuada. Revista Ciência \& Educação. v.15, n.2, p.343-358, 2009.

GIL-PÉREZ, D.; CARVALHO, A. M. P. Formação de professores de Ciências: tendências e inovações. São Paulo: Cortez Ed., 1993.

Krasilchick, Miriam. Formação de professores e ensino de ciências: tendências nos anos 90. In: Menezes, L.C. (org.) Formação continuada de Professores de Ciências: Nupes, 1996, pp.135-140.

Mello, R.M.A.V.de \& Oliveira, A. de M. A didática do ensino superior no processo de formação pedagógica nos cursos de pós-graduação da UFV e UFMG. In: Formação docente para o ensino superior. VIII Congresso estadual paulista sobre formação de educadores. Águas de Lindóia/SP Unesp. De 25 a 29 de setembro de 2005. P.63-70 
Mizukami, M.das G.N. \& Ferenc, A.V.F. Formação de professores, docência universitária e o aprender a ensinar. In: Formação docente para o ensino superior. VIII Congresso estadual paulista sobre formação de educadores. Águas de Lindóia/SP Unesp. De 25 a 29 de setembro de 2005.p.3-11

Neuenfeldt, Manuelli C. Formação de professores para o ensino superior: reflexões sobre a docência orientada.In: $\quad$ HTTP://www.ufsm.br/gpforma/2senafe/PDF/019e5.pdf $\quad$ Acessado em 15/novembro/2011.

Pachane, G.G. Programa de estágio e capacitação docente: a experiência de formação de professores universitários na Unicamp. In: Formação docente para o ensino superior. VIII Congresso estadual paulista sobre formação de educadores. Águas de Lindóia/SP Unesp. De 25 a 29 de setembro de 2005. P.12-21

Pimenta, Selma Garrido e ANASTASIOU, Léa das Graças Camargo. Docência no ensino superior. 3ed. São Paulo: Cortez, 2008 (Coleção Docência em formação)

Richit, Adriana. Apropriação do Conhecimento Pedagógico-Tecnológico em Matemática e a Formação Continuada de Professores. Tese de doutorado. Unesp, Rio Claro, SP. 2010. Orientador: Marcus Vinicius Maltempi

Silva, Rejane M.G. da \& Ferreira, Talita. Formação inicial de professores de química: identificando as necessidades formativas. In: http://www.pesquisa.uncnet.br Centro de pesquisa UnC - Universidade do Contestado - Concórdia/SC. Acesso em 10/maio/2012.

Silva, C.S. da \& Oliveira, L.A.A.de Formação inicial de professores de química: formação específica e pedagógica. . In: Ensino de Ciências e Matemática I: temas sobre formação de professores. org. Roberto Nardi. p.43-57, Editora Unesp. Bauru/SP, 2009. 


\section{PROFESSORES DE LICENCIATURA E BACHARELADO EM QUIMICA E FISICA}

UNIR Universidade Federal de Rondônia

Prezado Colega da Unir.

Meu nome é Liliane da Silva Coelho Jacon, sou docente do departamento de Ciência da Computação da Unir/PVH e doutoranda da REAMEC - Rede Amazônica de Educação em Ciências e Matemática.

Como parte da minha pesquisa, preciso coletar informações sobre o uso de computadores pelos docentes dos cursos de licenciatura da UNIR, tema da minha tese de doutorado (formação de professores).

Desta forma, o formulário é dividido em 3 partes:

A - identificação do docente

B - Formas de acesso

C - Formas de utilização do computador

Conto com a sua colaboração para preenchimento do formulário.

Atenciosamente,

Profa. Liliane Jacon - liliane285@ hotmail.com-(69) 9231-7264

A1- Identificação do Professor

Nome:

Email:

Data de Nascimento:

A2- QUAL SUA ÁREA DE FORMAÇÃO (curso superior)? Tipo de formação

\begin{tabular}{|l|l|}
\hline Ciências Físicas & \\
\hline Matemática & \\
\hline Química & \\
\hline Ciências Biológicas & \\
\hline Pedagogia & \\
\hline Outras & \\
\hline Se respondeu outras, cite qual .... \\
\hline
\end{tabular}

\begin{tabular}{|c|c|}
\hline & Bacharel (apenas) \\
\hline & Licenciado (apenas) \\
\hline & $\begin{array}{c}\text { Ambos -licenciado e } \\
\text { bacharel }\end{array}$ \\
\hline
\end{tabular}


A3-TITULAÇÃO (a maior obtida)

\begin{tabular}{|l|l|}
\hline & Pós-Doc \\
\hline & Doutorado \\
\hline & Doutorado incompleto \\
\hline & Mestrado \\
\hline & Mestrado incompleto \\
\hline & Especialização \\
\hline & Graduação \\
\hline
\end{tabular}

A4- Local de trabalho

\begin{tabular}{|l|}
\hline Campus \\
\hline Departamento \\
\hline Ano de Ingresso: \\
\hline
\end{tabular}

A5- Sexo
\begin{tabular}{|l|l|}
\hline & Masculino \\
\hline & Feminino \\
\hline
\end{tabular}

A6- Há quantoanosvocê atua comoprofessor?

(ANOTE A RESPOSTA - SE MENOS DE 12 MESES ANOTE 01 ANO)

\section{$1 \quad 1 \quad 1 \mathrm{ANO}(\mathrm{S})$}

A7- Você é contratado ouconcursado?

\begin{tabular}{|l|l|}
\hline Contrato temporário/ eventual & \\
\hline Efetivo/ Concursado & \\
\hline
\end{tabular}

\section{Seção B - FORMAS DE ACESSO}

B1- Você costuma acessar a Internetatravés do telefonecelular?

\begin{tabular}{|l|l|}
\hline Sim & \\
\hline Não & \\
\hline
\end{tabular}

B2 - Você/ possui um tablet?

\begin{tabular}{|l|l|}
\hline Sim & \\
\hline Não & \\
\hline
\end{tabular}

B3 -Você utiliza o computador nos seus afazeres acadêmicos?

\begin{tabular}{|l|l|}
\hline Sim & \\
\hline Não & \\
\hline
\end{tabular}

B4- Cite os lugares onde você utiliza o computador (notebook, desktop, tablet)

\begin{tabular}{|l|l|l|}
\hline & Casa (residencial) & Acesso à internet? ( ) sim ( ) não \\
\hline \multirow{2}{*}{} & Tempo de uso diário (médio): ...........horas \\
\cline { 2 - 2 }
\end{tabular}

\begin{tabular}{|c|c|c|}
\hline \multicolumn{3}{|l|}{ Universidade } \\
\hline & $\begin{array}{l}\text { ( ) Computador adquirido com } \\
\text { recurso próprio que você utiliza } \\
\text { na Universidade }\end{array}$ & $\begin{array}{l}\text { ( ) Computador da Universidade } \\
\text { na qual você tem disponibilidade } \\
\text { de acesso }\end{array}$ \\
\hline & Acesso à internet? ( ) sim ( ) não & Acesso à internet? ( ) sim ( ) não \\
\hline & Tempo de uso diário:...........horas & Tempo de uso diário : ...........horas \\
\hline
\end{tabular}


B5- Você tem disponibilidade de utilização dos laboratórios de informática da Universidade, para ministrar suas aulas?

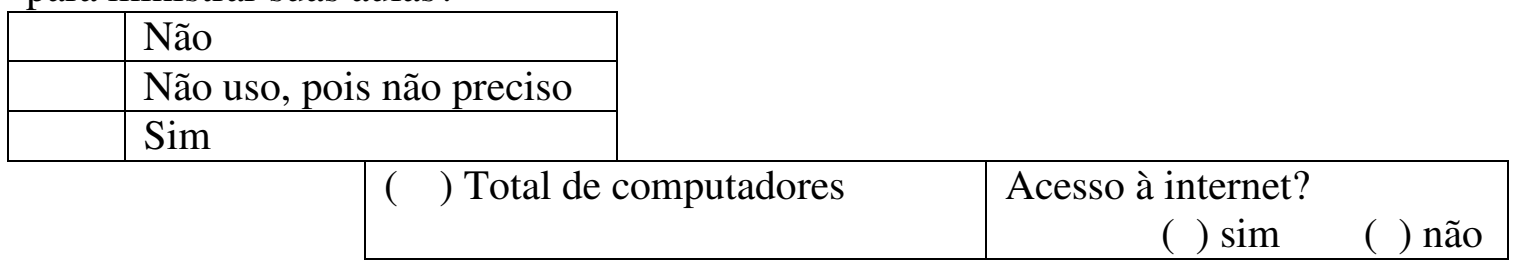

\section{Seção C - FORMAS DE UTILIZAÇÃO}

C1- O quantovocê diria quesuahabilidade no uso de computador é suficienteparaatender às suasnecessidadespessoais e atividades profissionais?

\begin{tabular}{|l|c|c|}
\hline $\begin{array}{l}\text { HABILIDADE NO USO DO } \\
\text { COMPUTADOR }\end{array}$ & NecessidadesPessoais & Atividadesprofissionais \\
\hline Minhahabilidade é muitoinsuficiente & 1 & 1 \\
\hline Minhahabilidade é insuficiente & 2 & 2 \\
\hline $\begin{array}{l}\text { Tenho habilidadena medidacerta / é } \\
\text { suficiente }\end{array}$ & 3 & 4 \\
\hline $\begin{array}{l}\text { Minhahabilidade é maior do que o } \\
\text { necessário }\end{array}$ & 4 & 5 \\
\hline $\begin{array}{l}\text { Minhahabilidade é muitomaior do que o } \\
\text { necessário }\end{array}$ & 5 & \\
\hline
\end{tabular}

C2 - Caso você utilize o computador na preparação de material didático para apoiar a sua prática pedagógica, responda cada item abaixo, numa escala de 0 a 10 . Observe que:

O significa quevocê não usa esta modalidade na elaboração do seu material didático

10 significa quevocê emprega fortemente esta modalidade na elaboração do seu material didático

FAÇA UM “X” em cima da nota para cada item abaixo (LEIA CADA FRASE)

\begin{tabular}{|c|c|c|c|c|c|c|c|c|c|c|c|c|}
\hline ITENS & $\begin{array}{c}\text { NÃO } \\
\text { utilizo esta } \\
\text { modalidad } \\
\text { e como } \\
\text { apoio } \\
\leftarrow\end{array}$ & & & & & & & & & & $\begin{array}{c}\text { Utilizo } \\
\text { fortemente } \\
\text { esta } \\
\text { modalidade } \\
\text { como apoio } \\
\text { na } \\
\text { elaboração } \\
\rightarrow\end{array}$ & $\begin{array}{c}\text { NÃO SE } \\
\text { APLICA } \\
\text { / NÃO } \\
\text { CONHE } \\
\text { CE A } \\
\text { ATIVID } \\
\text { ADE }\end{array}$ \\
\hline $\begin{array}{l}\text { Utilizo processador de texto para } \\
\text { a produção de material didático de } \\
\text { apoio as minhas atividades }\end{array}$ & 0 & 1 & 2 & 3 & 4 & 5 & 6 & 7 & 8 & 9 & 10 & 99 \\
\hline
\end{tabular}


pedagógicas (planos, provas, módulos de aprendizagem, materiais de leitura)

Utilizo planilha eletrônica na preparação de material didático de apoio aos processos de ensino e aprendizagem em meu setor curricular

Utilizo ferramentas
computacionais para o desenvolvimento de recursos multimídia de apoio às atividades pedagógicas (elaboração de páginas web, uso de editores de páginas web e/ou aplicações para seu desenvolvimento. Por exemplo dreamweaver.

Crio apresentações para apoiar o ensino e a aprendizagem de conteúdos de meu setor curricular utilizando elementos textuais, gráficos e multimídia contidos em software de apresentação

Crio e publico materiais em plataformas de trabalho colaborativo com o fim de criar espaços virtuais de aprendizagem e reconhecer o potencial educativo das comunidades virtuais (Moodle, teleduc, webquest)

Utilizo software educativo específico da minha área de conhecimento, como apoio ao processo de ensino aprendizagem com seus alunos

Crio e mantenho base de dados para armazenar e consultar informações da minha área do conhecimento (ex; MySQL, Oracle, Access, etc)

\begin{tabular}{|l|l|l|l|l|l|l|l|l|l|l|l|}
\hline & & & & & & & & & & & \\
\\
\hline
\end{tabular}

Muito obrigada pela colaboração! 